Portland State University

PDXScholar

1972

\title{
A case study of the Northwest District Association and Portland City planning staff
}

\author{
Jill Sally Haldeman \\ Portland State University \\ Kathryn Cynara Heisler \\ Portland State University
}

Follow this and additional works at: https://pdxscholar.library.pdx.edu/open_access_etds

Part of the Social Work Commons

Let us know how access to this document benefits you.

\section{Recommended Citation}

Haldeman, Jill Sally and Heisler, Kathryn Cynara, "A case study of the Northwest District Association and Portland City planning staff" (1972). Dissertations and Theses. Paper 1644.

https://doi.org/10.15760/etd.1644

This Thesis is brought to you for free and open access. It has been accepted for inclusion in Dissertations and Theses by an authorized administrator of PDXScholar. Please contact us if we can make this document more accessible: pdxscholar@pdx.edu. 
A CASE STUDY OF THE NORTHWEST DISTRICT ASSOCIATION

AND PORTLAND CITY PLANNING STAFF

by

JILL SALLY HALDEMAN

and

KATHRYN CYNARA HEISLER

- A practicum submitted in partial fulfillment of the requirements for the degree of

Master of Social Work

Portland State University

1972 
TO THE OFFICE OF GRADUATE STUDIES:

The members of the Committee approve the thesis of Jill

Sally Haldeman and Kathryn Cynara Heisler presented June 7, 1972.

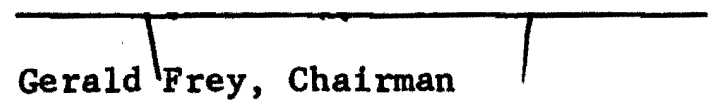

David Yaden

APPROVED :

Gordon Hearn, Dean of School of Social Work 
TABLE OF CONTENTS

PAGE

ACKNOWLEDGEMENTS $\ldots \ldots \ldots \ldots \ldots \ldots \ldots \ldots \ldots \ldots$ i

CHAPTER

I INTRODUCTION.................. 1

II $\operatorname{HISTORY} \ldots \ldots \ldots \ldots \ldots \ldots \ldots \ldots \ldots \ldots \ldots \ldots$

III N.W.D.A. - SŢAFF RELATIONSHIP....... 20

IV SUB-COMMITTEE WORK AND NEIGHBORHOOD MEETINGS ............ 27

v FREEWAY ISSUE................. 40

VI GOOD SAMARITAN HOSPITAL ISSUE....... 52

VII CONCLUSION.................... 59

VIII SUGGESTED POLICY FOR

DISTRICT PLANNING............. 67

BIBLIOGRAPHY $\ldots \ldots \ldots \ldots \ldots \ldots \ldots \ldots \ldots \ldots \ldots \ldots \ldots \ldots$ 


\section{ACKNOWLEDGEMENTS}

We wish to extend our thanks to the members of the Northwest District Association, who allowed us to attend any meetings we desired and willingly gave of their own time in individual interviews. We are also grateful for Mr. John Perry and Mr. Dave Richen, PCPC Staff, who contributed much to the content of this practicum. We wish to pay a special tribute to $\mathrm{Mr}$. Gerald Frey and $\mathrm{Mr}$. David Yaden, our practicum advisers, for their suggestions and encouragement. They played a major role in the development of this practicum. We also wish to thank Mrs. Richard Stensrud for her help in reviewing and editing the final draft. 


\section{INTRODUCTION}

This is a study of how a city planning staff worked together with a neighborhood group to develop a comprehensive plan for a neighborhood. It explores their relationship and the major conflicts that arise whon they work together to develop a district plan.

Today the planning profession is shifting from planning for the people to planning with them. Added to this change is the companion shift from large scale government institutions on both the metropolitan and federal levels to a stress on decentralization to neighborhood units. ${ }^{1}$ The principles underlying this shift in emphasis are that in a democracy it is important for citizens to be allowed to participate in making decisions: that professional planning needs suggestions from neighborhood participation groups. Therefore, the planning of specific changes in the social and physical order of a local community should be decentralized, and the persons most affected by these changes should participate through formal associations in defining both the goals and the means for these changes. Through these associations and collective action, individuals who are otherwise in a disadvantaged position in the local community can have more power in determining what happens to them. ${ }^{2}$

Examples in this shift toward citizen participation can be seen in the part it played as the key element in the federal government's Juvenile Delinquency Demonstration Program, The Community Action Programs and Mode1 Cities. The move toward citizen involvement in the public-private policy coalitions in the Juvenile Delinquency Programs was advisory rather than decision-making. The neighborhood groups involved provided feedback for the central planning agency and helped to implement its program. The emphasis of the program was on cooperation between neighbors rather than confrontation with public agencies controlling the resources for the neighborhood. 3 
In the Community Action Program, as in the Juvenile Delinquency Program, much of the neighborhood organization was concerned with linking people to services and building a constituency for the program. However, in Community Action Programs the neighborhood began to emerge as a partner and, in some projects, a controlling force in the decision-making process. 4

The provision for "widespread citizen-participation" in the basic Model Cities legislation has been interpreted in the context of a growing social movement by neighborhood residents toward a larger role in neighborhood and city-wide decision-making. In many cities the planning stage of Model Cities has been characterized by a power struggle between neighborhood groups and city hal1.5

City planning departments are also using citizen participation in planning neighborhoods. Just as there are varying degrees of citizen participation in planning for federal programs, there are varying degrees of citizen involvement and quality of involvement in non-federally funded neighborhood planning programs.

When city planners work together with citizens an interdependency between the neighborhood association and the city planning department develops. The neighborhood association is dependent upon the planning department for support, staff and legitimacy in order to produce a comprehensive plan for the neighborhood. The city planning department is likewise dependent upon the neighborhood association to develop a plan acceptable to the neighborhood. This interdependency makes the relationship between the neighborhood and the planning department crucial.

There are three basic models of neighborhood-agency relationships which can evolve. 6 One is that in which the agency sponsors the neighborhood 
association. The agency provides staff and resources to the neighborhood association, and, although the association may advise the agency on a policy, the agency remains the central decision-making member. This relationship is most effective for programs which emphasize services rather than social action or institutional change.

Another model is that in which the agency provides staff services to a nominally independent neighborhood association. Although the policy-making is in the hands of the neighborhood association, its dependency upon the agency for resources, such as staff, technical assistance and access to power often means that the independence is more theoretical than real. In this model the emphasis is on consensus of agreement rather than conflict, and, as in the case of a sponsoring agency model, the neighborhood rarely deals with Institutional change. Since the nature of this relationship is relative, the very difficulty in defining the precise relationship often creates tension within and between the agency and neighborhood association when new issues arise.

The final model of agency-neighborhood relationship is characterized by a completely independent neighborhood association where the agency acts as simply another participant in the planning venture. Both association and agency are seen as equal partners and some type of agreed upon contract governs their relationship.

This agency-neighborhood association relationship is further complicated by the three way relationship which exists between the core leaders of the association, the planning agency, and the individual or individuals who are the primary channels for transmitting assistance from the agency to the association.7 This relationship can generally be handled if the association focuses on local problems, the delivery of services, and uses tactics other than conflict to accomplish its goals. Even under such conditions the relationship is at best unstable. 
This shift to citizen participation in planning and the need to define the agency-association relationship is producing a need for a planner to redefine his role with respect to both the neighborhood association and the planning agency.

The traditional role of a planner has been that of a technician or expert capable of analyzing a situation and then outlining a policy that has been rationally selected on the basis of his analysis. The planner as technician wants his plan to be implemented but he does not regard himself as the promoter of the plan. The role of technician is effective in a cohesive political community where the planner shares the goals of the leadership group. In this situation he has substantial ability to effect the plan development as long as he does not violate the established goals and means of goal attainment of the community.

Where at least two groups compete for leadership in a community, the planner must assume the role of broker. In such a role he not only referees the competition between the groups but also seeks to pyramid the support of persons he believes can be beneficial and identifies the point at which the groups can agree.

Mogulof suggests that the planning experience of Model Cities demonstrates that the social-broker role is no longer viable. 8 Instead, the planner must commit himself to both a constituency and a plan, and actively advocate them. The role then of an advocate planner is especially applicable in a fragmented community, where the issues involved are basically political in nature.

While the planner is redefining his role in the emerging neighborhoodagency relationship; so, too, is the neighborhood association. Arnstein suggests that there is a critical difference between going through the ritual of citizen participation and actually having the power to effect the outcome of a planning process. She divides the degree of citizen participation into three levels: 
nonparticipation, tokenism, and citizen power. 9 Each of these general categories defines the rights and responsibilities of the neighborhood in the planning process. Nonparticipatory roles exist where the association gives rubber stamp approval to plans already formulated by the experts and thus fulfills the need for grass-roots involvement in the program. It also exists where the association is seen as a powerless group in need of help. A tokenism role is played by an association whose primary purpose is to inform, act as consultants, or placate a neighborhood where planning is occurring. In such a role, much ambiguity may result. The association is asked to advise the planners as to the needs of the neighborhood, yet the final right to judge the legitimacy or feasibility of the advice is not given to the association. Finally, a neighborhood association exhibits a true role of citizen power where, either through an equal partnership arrangement, delegated authority, or complete control of a program, the association has decision-making power.

These changing role expectations for both the planner and neighborhood association are a potential source of confusion and misunderstanding when a neighborhood association, and a city planning department and its staff, are attempting to define their relationship and work together on a comprehensive plan for the neighborhood. The planner, for example, may experience conflict between the demands of his profession as to what plan is best for the area and the city as a whole, and the demands of the association that he advocate the plan they deem best for their neighborhood. The neighborhood, on the other hand, may desire a partnership arrangement with the planning department in order to assure more decision-making power and yet lack either the resources or committment to carry, out the responsibilities, that this relationship involves. This confusion in role expectations and perceptions can result in possible failures in planning for the neighborhood. There may be a lack of organizational 
skills, due to failure in defining what party is responsible for leadership and initiative in projects. This could result in an inability to define manageable problems or deal with basic issues. Failure to define clearly the agencyneighborhood relationship might also result in a lack of sophistication in dealing with city officials, and a lack of access to the power structure. Finally, confusion within the agency-neighborhood relationship and resulting inefficiency in planning can lead to apathy on the part of members of the association, and the association falling into general ill-repute in both the neighborhood and in city hall.

The elimination of role confusion is vital to successful neighborhood planning. To eliminate possible confusion, the planning department must be explicit in its intentions. The department must be specific as to its goals, expectations and limitations in working with the association and communicate these clearly to the association. Secondly, the association must clearly define for itself its goals, expectations, and limitations in representing the neighborhood and working with the planning department. This must be clearly communicated to the planning department. The planner for the area does not have to experience divided loyalties between agency and association if the agency is clear in its purpose in providing staff for the association. "A candid, honest presentation of goals, expectations, and limitations helps the community assess the implications of working with the agency. In such an approach, respect for the community is conveyed and the integrity of both the agency and the community is maintained."11

Goals and role expectations change with varying issues; effective planning demands a reclarification of roles on the part of both planner and association. A relationship between planner and association should emerge when goals and role expectations are clearly expressed and agreed.upon.

In terms of the developing citizen participation in urban planning, the Northwest District Association and the Portland City Planning Department is 
one model which can evolve. In this model the Northwest District Association is an independent neighborhood association that developed a working agreement with Portland City Planning Staff to create a comprehensive plan for their district.

In Portland, Oregon, the idea of involving citizens with city planning is relatively new. No guidelines as to specific roles and tasks for the Planning Staff and the Northwest District Association were offered before they developed their relationship. The idea of citizen participation in the area of comprehensive planning is in an experimental stage and it is not clear what is implied by allowing "citizen participation", or citizen input". It was decided that important guidelines to successful planning might be found by exploring roles and role expectations for both Portland City Planning Commission Staff and the Northwest District Association. This study explores the terms of the original relationship and how these terms were communicated. Then it explores how the role expectations which evolved from this relationship changed and how these changes were clarified and communicated.

How the role of planner and the role of NWDA is defined will determine who assumes the initiative for projects, who is responsible for their completion, and who influences the direction and scope of the comprehensive plan being produced for the area. Where the planner-NWDA relationship, responsibilities and rights are clearly defined and communicated, and the terms of the relationship and its goals are compatible, effective joint planning should occur. When role expectations are unclear or are in conflict friction and mutually unacceptable or ineffective project cooperation can be expected.

\section{Methodology}

Initially, in exploring the relationship between the Northwest District Association (NWDA) and Portland City Planning Commission Staff (PCPC Staff), 
members of the NWDA Board of Directors and Sub-committees and PCPC Staff were questioned through open-end interviews. The eleven NWDA members and three PCPC Staff interviewed were asked to describe their relationship, the conflicts that arose between them and what had been successfully accomplished. As the interviews continued it became apparent that certain issues suggested major areas of role confusion. The questions became more specific and centered around three areas: 1) how NWDA members defined their role of citizen input and participation, 2) to whom Staff was accountable, and 3) who accepted initiative and responsibility for the various planning tasks. To give examples of these three issues this study explored four areas in which NWDA and PCPC Staff were involved. First, the general working relationship between NWDA and Staff was explored. Second, this study explored the development of NWDA sub-committees and neighborhood meetings. Third, the relationship that developed around the proposed freeway through the neighborhood was studied. Finally, the study explored the role that NWDA and PCPC Staff played regarding the expansion of a major metropolitan hospital in Northwest Portland.

In developing the Northwest Comprehensive Plan, it became apparent that certain guidelines would minimize confusion in joint PCPC Staff-Neighborhood planning and maximize their joint planning capabilities. The final chapter of this study summarizes the relationship between NWDA and Staff and suggests guidelines for future PCPC Staff-Neighborhood association planning.

Within this study "NWDA" refers to the NWDA Board of Directors and Subcommittee chairmen and "PCPC Staff" or "Staff" refers to the two planning department staff who were hired by PCPC to work with NWDA. The relationship that developed centered around the se two groups. 13

In addition to the interviews, further information was gathered by regularly attending NWDA meetings and reviewing NWDA and PCPC Staff files of minutes and correspondence. 
The following chapter focuses upon the history of the NWDA, how the neighborhood association was formed, why it was formed, and what issues led to the development of the NWDA-Staff relationship. 


\section{Footnotes}

1 Alan Altshuler, "Decision-Making and the Trend Toward Pluralistic Planning", Urban Planning in Transition, 1970, p. 183.

2 David M. Austin, "Influence of Community Setting on Neighborhood Action", Neighborhood Organization for Community Action, 1967, pp. 76-93.

3 Melvin Mogulof, "Coalition to Adversary: Citizen Participation in Three Federal Programs", AIP Journal, July, 1969, p. 226.

4 Ibid, p. 230.

5 Ronald L. Warren, "Model Cities First Round; Politics, Planning and Participation", Journal of the American Institute of Plianners, July, 1969, p. 245 . p. 41.

6 Making Democracy Work; A Study of Neighborhood Organization, New York,

7 Austin, op. cit., p. 93 .

8 Mogulof, op. cit., p. 230 .

9 Sherry R. Arnstein, "A Ladder of Citizen Participation", AIP Journal, July, 1969, p. 217 .

10 Making Democracy Work: A Study of Neighborhood Organization, op. cit., p. 64 .

11 Ibid., p. 44.

12 A department of the city important to the preliminary development of the relationship is the Portland Development Commission, who are called PDC. They are a powerful segment represented on City Council since they are recipients of direct federal funding. 


\section{HISTORY}

The beginnings of neighborhood involvement in Northwest Portland occurred in 1959. Friendly House, a community service agency, held a meeting to discuss the new freeway that was being built through the northwest part of Portland. Residents were concerned where the freeway corridor would be placed and how it would effect their neighborhood. Little was accomplished at these initial meetings and interest soon died out.

Later, a group composed primarily of ministers formed in the Northwest to discuss zoning variances. The ministers were interested in preserving residential areas in Northwest Portland. Zoning variances can allow for increasing Industry and large businesses which make a neighborhood less compatible for residents and churches: A minister in the area, who later became the first president of the NWDA, led the group.

In 1964 Good Samaritan Hospital Board of Trustees decided that the hospital would remain within Northwest Portland and a major modification program kegan to bring the hospital to current standards and to buy land for proposed additions. At this same time a large business, Consolidated Freightways, began talking about expanding in Northwest. Portlland. These expansions would push more residents from the neighborhood.

The hospital and Consolidated Freightways were considered the prime movers in studying the environmental problems of Northwest Portland. ${ }^{1}$ In 1969 , at the request of Good Samaritan Hospital, Physicians and Surgeons Hospital and Consolidated Freightways, Portland Development Commission (PDC) studied the prospect . of federal aid for a Neighborhood Developmental Program (NDP). However, the hospitals' and the industry's prime interest in an NDP grant was to use urban renewal as a means to acquire property for expansion. This expansion would Involve tearing down old homes and apartments. The grant applied for through PDC was for 15 blocks of urban renewal. 2 
PDC felt an interest group was needed to back the urban renewal project and they sent a representative to approach several churches, Friendly House and other Northwest Portland citizens, to ask them to form a community action group. These citizens were skeptical of PCD's interest in the neighborhood. They contacted Portland State Unfversity Department of Urban Studies and asked for someone to help them. Later, one professor became involved in NWDA's' subcommittees.

In March of 1969, Friendly House held an annual meeting. The agenda included the discussion of possibilities for an NDP grant. One of the Urban Studies' professors said there was a strong commitment from the federal government for citizen participation in a Neighborhood Development Plan (NDP). He added that citizen participation creates the possibility of allowing community residents more influence in an urban renewal project. Federal aid for the NDP grant seemed promising.

Later, PDC, initially believing the plan to be accepted favorably, was informed by the U.S. Department of Housing and Urban Development (HUD) that they had decided not to approve any more NDP programs. This action eliminated Consolidated Freightways from any part in other federally funded environmental studies because only non-profit institutions, such as hospitals and universities, can take advantage of urban renewal to expand facilities. Good Samaritan Hospital continued with its request for an urban renewal project.

Friendly House and the ministers saw the need for the development of a formal citizen participation group in the neighborhood as a result of PDC's request for citizen participation. They decided to hold a public meeting to create the neighborhood group. On May 15, 1969, the first public meeting was held and they named the group the Northwest District Developmental Association. 
Later they changed the name to Northwest District Association (NWDA) to avoid the confusion of being linked with Portland Development Commission. At this time no city planning staff was yet involved. Tha constitution for the association, presented at this meeting stated,". . the object and purpose of this organization shall be to encourage, coordinate, plan and participate in the orderly rehabilitation and renewal of that portion of the Northwest section (of Portland)..$^{3}$

That spring Good Samaritan Hospital approached NWDA with the possibility of holding a public meeting, in Northwest Portland to gain a community response to their decision to remain and expand in the area, and a response to their request for a grant to take advantage of urban renewal for this expansion. NWDA felt that the proposed freeway, also, should be discussed at this meeting. In addition, they wanted to present the by-laws for acceptance. NWDA publicized the meeting and asked that citizens attend to take an active part in decisions being made that would effect their neighborhood.

The meeting was held May 20, 1969. Presiding at the meeting was the minister who was active in forming NWDA and who became the first president. He was interested in leading an organized meeting and in passing NWDA's constitution, which was eventually accomplished inspite of the other distractions. An angry crowd of 450 people met to respond primarily to Good Samaritan administrators. The administrators had expected a more congenial group. PDC, backing Good Samaritan at the meeting, also received a negative response from the group.

At the meeting Good Samaritan Hospital proposed an expansion toward Physicians and Surgeons' Hospital, to eventually provide a complete medical complex. One of the administrators said that the hospital needed to expand in order to keep pace with "tremendous changes in health care in the past five 
years." He believed the hospital plan would create a buffer between residential areas and "encroaching industries". 4 PDC said they would submit a plan to HUD by Octobex, 1969, for application for federal funds. According to HUD's stipulations, urban renewal efforts would include housing rehabilitation and code enforcement, as well as property acquisition, demolition and redevelopment.

The people attending the meeting were generally in disfavor of the proposals. The crowd was disorderly and abusive to the Good Samaritan administrators. Several residents said the government had no right to force them from their homes and businesses in order to accomodate the hospital. ${ }^{5}$ The people at the meeting made it clear that they were displeased with Good Samaritan and PDC. At the end of the meeting Good Samaritan and Northwest residents were still dissatisfied with one another.

During the summer of 1969 , NWDA established the structure for their association. NWDA decided to divide itself into various sub-committees that would be responsible for particular areas of interest within Northwest Portland. For instance, NWDA established a Land Use and Zoning sub-committee. This committee responded to petitions for zoning changes that contributed to destroying the "livability" of the neighborhood. They would help the residents fight the zone change. During this time NWDA developed the idea that they contribute to planning for their district. Some NWDA members spoke informally with the Portland City Planning Commission and Lloyd Anderson, a city commissioner, about their idea. NWDA wanted to be able to work with PCPC and express their opinion on what should be done in their area. NWDA was also exploring avenues for acquiring a paid staff to help with the planning.

- Finally in November, 1969, City Council was to consider Good Samaritan Hospital's proposal for an urban renewal project. NWDA prepared to present. 
their opinions on this proposal. PDC had prepared an application to HUD for the planning grant in cooperation with the hospital and its architectural consultants. Federal regulations required that the proposal first be a.proved by City Council before application could be made to HUD. The meeting was a regular City Council hearing, with other interested citizens present.

At the hearing Good Samaritan presented their proposal and arguments for it to the council. The proposal was for $\$ 199,217$ from HUD for survey and planning costs for urban renewal in Northwest Portland. Good Samaritan Hospital reported that they proposed to use Northwest land for the development of 1,500 parking spaces, construction of new facilities for the Rehabilitation Institute of Oregon, ambulatory and diabetic care centers, 400 units of low cost housing for the elderly, commercial area for offices, shops, supermarkets and motels, nursing dorms, recreational facilities, research and educational facilities and a doubled number of hospital beds. The provision stipulated that there must be a feasible method of relocating displaced residents and that the hospital fund one-third of the project cost.

PDC, backing Good Samaritan Hospital at the hearing, said that in 1966 Portland City Planning Commission had reported on a Community Action Program that was being considered for the Northwest district. PCPC noted chaotic land use, overcrowded and dangerous streets, a lack of parks and open space, substandard housing and a disproportionate number of elderly people. PDC argued that the proposed land uses in the hospital planning request would be consistent with that comprehensive plan by PCPC in 1966. PCPC noted that the comprehensive plan needed to be updated.

NWDA members presented in an orderly fashion their arguments. They said that they were not opposed to Good Samaritan's project but favored the study of a larger portion of the Northwest area. They asked that City Council delay 
action on the hospital's planning request pending an area wide study on "trends and the impact of spot urban renewal in the area."6 Discussion at the hearing consisted of pros and cons of the feasibility for the Good Samaritan project planning and broader area-wide planning to be accomplished simultaneously. PDC wanted to apply for federal planning funds immediately but conceded the money might not be available for a year or more. NWDA wanted a comprehensive study to determine what impact the proposed project would have on the area's social, economic and physical environment; but the short-staffed Planning Commission felt they did not have the manpower or resources to do the study. PDC approved of the Planning Commission working with the Northwest district residents in developing an up-to-date area plan that could be completed by the middle of 1970 . They urged the 'City to apply for funds to assist the Planning Commission in carrying out this work.

Some members of City Council were hesitant about approving Good Samaritan's proposal. One city commissioner warned the City Council of the serious problem which might arise if the Council approved filing of the Good Samaritan proposal and later ran into unexpected costs and community opposition concerning street closures and other construction phases. Someone else argued that approval of the application did not imply approval of project details. PDC said the local share of the project could be paid entirely by the hospital. Completion of the project would mean 1,478 new jobs and $\$ 15$ million for the Good Samaritan Hospital complex alone. 7

It became evident at this Council hearing that no decisions could be made without exploring possible complications and how they could be resolved. The mayor instructed two City Commissioners to work together and report back at a public hearing on the planning capabilities of the City's engineering and planning 
departments. These commissioners researched the problem and then worked out a proposal at a small closed meeting with the mayor prior to the public hearing. The public hearing was held on Derember 10, 1969. NWDA spoke again on involving the people of the neighborhood in any type of urban renewal project. 8 The two commissioners, asked to report on the City's planning capabilities, presented the following recommendations to the Council: the approval for PDC to apply to HUD for a planning grant; approval for an urban renewal study and a separate comprehensive study of the Northwest District with the broader study being performed prior to or simultaneously with the 15-block urban renewal project study; approval of a budget of $\$ 75,000$ in the coming fiscal year for PCPC to study and make preliminary design studies on the Northwest district streets and sewers; and that PCPC Staff prepare a comprehensive plan for the Northwest district in cooperation with the area residents and interest groups. 9 The Portland City Council adopted these recommendations. They also agreed that NWDA would involve people fron the community to share in the work of the comprehensive plan. Staff would begin work in July, 1970.

The NWDA planning committee began to meet immediately after the council meeting of December, 1969. That spring NWDA was busy with their involvement with the proposed freeway, trying to find out what could be done to produce the least amount of disruption in the neighborhood. During the spring and summer NWDA continued their involvement in fighting zoning variances. They also spent time learning more about what their members wanted in the community and what was being planned for the area. For example, NWDA had the City's bus company present their future plans for the district. NWDA also tried to increase their membership.

A preliminary contact between NWDA and PCPC Staff developed in March of 1970, concerning the proposed I-505 Freeway corridor to cut through Northwest 
Portland. PCPC requested that their staff meet with representative groups of the Northwest district concerning six alternative plans for freeway elevation, alignment and multiple use and development on I-505 and I-405 proposed freeways. The Staff, different from Staff later involved in the comprehensive plan, met on two occasions in the Northwest area. Staff presented freeway alternatives and NWDA voted on them. 10

PCPC Staff were authorized to begin work with NWDA in July of 1970. There were varying ideas and much confusion as to how the City Planning Staff would work with NWDA. No one was even certain who on the PCPC staff would work with NWDA. NWDA expected one staff member to represent PCPC because he lived in Northwest Portland. What actually occurred was that Portland City Planning Staff designated another member to begin work in the late summer. Shortly after his involvement PCPC also hired another staff person to work with NWDA. PCPC Staff began to attend meetings in the late summer of 1970 , getting acquainted with its members and trying to develop a plan for working with them.

By November, 1970, the initial relationship between NWDA and Staff was established. Planning Staff set the stage for developing hypothesis about the neighborhood which would be the basis for a comprehensive plan. The formal working relationship actually began at these meetings. 
1 William Sanderson, "N.W. Portland Has Unique Opportunity to Plan Neighborhood, Says Gervais", The Oregonian, March 14, 1969.

2 The Oregonian, May 22, 1969

3 "Northwest District Association Constitution," May 15, 1969.

4 William Sanderson, "450 Hear Plans Revealed for N.W. Urban Renewal," The Oregonian, May 22, 1969.

5 sanderson, loc. cit.

6 Frank Barte1, "Community Reaction May Snarl Good Samaritan Hospital's Urban Renewal," The Oregonian, November 24, 1969.

7 "Good Samaritan Urban Renewal Plans Snagged Over Disagreement," The Oregonian, December 3, 1969.

8 Interview with Dave Yaden, PCPC Staff, July 22, 1971.

9 The Oregonian, December 21, 1969.

10 Letter to Portland City Planning Commission, from Portland City Planning Department Staff, March 30, 1970. 


\section{N.W.D.A. - STAFF RELATIONSHIP}

At the time that PCPC Staff undertook the task of developing a comprehensive plan for Northwest Portland, the City Planning Commission had neither a policy statement outlining the goals for joint PCPC-neighborhood planning nor a set of guidelines clarifying the role of its Staff working with neighborhood planning associations. The Northwest Comprehensive Plan was essentially a pioneer project and Staff had the responsibility to define their role in the plan development. The preliminary contact between NWDA and Staff in November of 1970 , regarding the I-505 corridor through Northwest Portland, and the following meetings between NWDA and Staff provided the basis for the relationship which was to develop between the two. Throughout this relationship, Staff worked with essentially a core group of about fifteen citizens who were active on the Executive Board of NWDA and its Planning Committee. Therefore, when reference is made to the NWDA, or NWDA members, unless otherwise specified it refers to this core group of citizens who actually worked with Staff.

In the beginning of this relationship, NWDA held varying expectations for Staff and NWDA in working together to develop a plan for the district. For example, several NWDA members said they expected Staff to take a leadership role. According to their expectations, Staff would specify what work needed to be done and then people from the neighborhood who had some knowledge of planning would commit time to work with Staff. Staff, in this case, would provide direction and leadership for the plan development, and NWDA would review . and comment on the work done by Staff.

Other NWDA members expected Staff to assume a co-partnership role with the NWDA in developing the plan. One member explained this as meaning that Staff would provide technical assistance while NWDA would provide information regarding citizen attitudes and goals for the neighborhood. For example, 
NWDA would suggest land uses or traffic routes compatible with their goals for the neighborhood, and Staff would provide technical assistance in studying the feasibility of these suggestions and proposing alternatives.

Still other NWDA members expected Staff to act as technicians at the service of the NWDA. According to them, NWDA would assume the leadership role and Staff would work for NWDA although their salary was paid by the City. This group of NWDA members was further divided between those who expected Staff to work for NWDA as technicians -- that is, collecting data, doing studies, and drafting plans -- and those who expected Staff in addition to this technical role to act as advocates for the NWDA at the Planning Commission and City Council.

Staff, in defining its role with NWDA, felt that because NWDA had taken the initiative in approaching City Council and requesting a comprehensive plan for the district that they, NWDA, would continue in a leadership role throughout the planning process. Therefore, Staff defined their relationship with NWDA as a co-partnership. Staff would provide technical expertise in developing the plan and the NWDA would provide expertise in organizing and providing for citizen involvement in the planning process.

At the November 24, 1970, meeting of the NWDA Planning Committee, Staff presented a graph showing the general breakdown of responsibilities for Staff and NWDA in working together to develop the plan for the neighborhood. The purpose of the graph was to establish policy regarding joint NWDA-Staff planning. The role of Staff was essentially technical. Staff was to coordinate the technical efforts of NWDA, organize the information gathered by NWDA and Staff so that it could be readily used by the Planning Committee, and be at the service of NWDA for any material or direction they might need. The role of NWDA was political. NWDA was to involve neighborhood residents in the plan, do studies to ascertain neighborhood needs, develop planning goals for the 
neighborhood, and, through citizen involvement, establish political support for the plan. Staff then assumed the traditional non-political, technical planner role.

Confusion, then, marked the early relationship between Staff and NWDA. NWDA was not, as a group, wholely in agreement as to their expectations for themselves, nor for Staff in working for a district plan. Disagreement existed over who, NWDA or Staff, was to initiate activities, to whom Staff was accountable, and the extent to which Staff would advocate for NWDA. Staff, on the other hand, was in effect attempting to establish guidelines for neighborhood planning while working with the NWDA. Staff initially defined their role as non-political, technical planners working in a co-partnership with the NWDA. However, as will be seen later, this lack of certainty on the part of both NWDA and Staff as to what was specifically required of each in jointly developing the plan, created additional confusion.

As a result of some of the issues encountered in attempting to work with neighborhood planning associations, one of the Staff prepared a proposal for a City Policy Statement on District Planning in April, 1971. Although the guidelines set forth in the proposal were not accepted by the Council, the majority of NWDA members indicated that the proposal served to clarify for them the role of Staff and NWDA, and that this provided a clearer direction for them In developing the comprehensive plan.

Specifically the proposal read:

The Planning Commission is committed by this resolution to provide a specified amount of technical planning assistance to the DPO (District Planning Organization). The basic data on population, social factors, land use, building conditions, and neighborhood facilities should be provided, as well as other field surveys normally associated with a district plan. 
The Staff of the Planning Commission works very closely with the DPO in the development of goals and objectives, and finally specific plan proposals for the district. In its role as technical advisor, the staff proposes alternatives to the DPO and calls their attention to emerging problems and conflicts. But plan decisions are always made by the DPO.

The Staff is responsible for maintaining contact with other City bureaus, testing ideas generated by the district against the practical and technical knowledge within City government. Many City bureaus conduct specialized district studies as a routine matter (housing conditions, traffic studies, etc.). These bureaus should, whenever possible, coordinate their efforts with the Staff of the Planning Commission to ensure a unified City effort.

Often a DPO will want the benefits of a special study or request assistance that goes beyond that which can be provided by the City; perhaps an economic study, a soils study or legal counse1. The DPO should be prepared to assume responsibility for these studies, either through volunteer efforts or through fund raising.

When the DPO arrives at a plan for their district, the Planning Commission Staff prepares a rough draft for a hearing before the Planning Commission. The plan and public hearing should receive wide publication.

The Planning Commission asks the following questions of the plan:

1. Is it desirable from the standpoint of implementation over a reasonable period of time?

2. Is it truly representative of district needs and desires?

3. Is it in harmony with city-wide plans?

Reports on the draft plan should be submitted to the Planning Commission by affected City Bureaus or other public agencies; these might include the Traffic Engineering, Public Works, and Park Bureau and School District One.

After a hearing the Planning Commission submits its recommendations on the plan to the Council and the DPO. The DPO has the option of accepting or rejecting the recommendations, and the final DPO plan is prepared by the Staff for submission to the City Council.1

Although the Planning Commission's policy statement on district planning did help to clarify the role of Staff and NWDA, the following sources of confusion in role expectations were expressed in interviews throughout the planning process by both NWDA members and Staff. 
As stated earlier, a question existed as to who was to initiate and be responsible for activities during the planning process. After Staff and NWDA had been working together for several months, the general concensus in NWDA was that, ideally, NWDA should assume responsibility in providing citizen involvement and developing the set of goals for the neighborhood. However, NWDA members, because they were volunteers, at times neglected their work. Staff then had to assume the initiative in some activities and fill in the areas of work which NWDA failed to complete. For example, staff contacted businesses in the area to obtain their attitudes toward planning goals for the district when the Business Sub-committee failed to involve area business in the planning. Staff defined responsibility for projects in terms of general tasks to be completed and deadlines to be met by Staff and NWDA. Staff did not partialize the tasks to be performed by NWDA nor did NWDA do this. This failure to partialize tasks contributed at times to the inadequate use of volunteer and Staff time.

A second source of confusion was the question of Staff accountability. To whom was Staff to be accountable, NWDA or the Planning Commission? Some NWDA members expressed concern that Staff essentially belonged to the Planning Commission and, therefore, could not be completely trusted. Others felt that because of the close working relationship between Staff and NWDA, Staff would loose credibility with the Planning Commission and be seen as siding with the neighborhood. Many NWDA members believed that Staff should be their advocate at the Planning Commission and at City Council. However, Staff felt that politically they had no leverage--that this was to come from citizen backing of the plan. Also, under the issue of Staff accountability was the question as to what extent did Staff, because of their job as staff of the City PIanning Commission, have responsibility for insuring that interests other than those of 
NWDA; for example, business, hospitals, industry, be represented in the plan. In other words, the Staff's constituency was not clearly defined.

Fina 1.1y, the role of NWDA was essentially to provide citizen input and backing for the neighborhood plan. However, citizen input was never adequately defined. How many people were to be included? Who was to be included? How was this citizen input to occur? All these questions needed to be clarified for NWDA. Some members felt that NWDA was to provide voluntary professional assistance in plan development from citizens in the neighborhood. Others felt that a broader definition of citizen participation, that is involvement of the poor, the elderly and the single people in the area was needed.

In summary, neither Staff nor the NWDA clearly understood their own expectations for joint Staff-NWDA planning when they undertook development of the Northwest Comprehensive Plan. Both had to attempt to resolve this confusion throughout the entire planning process. Three major areas of confusion Initiation and responsibility for specific tasks, Staff accountability, and clarification of the concept "citizen input" - reoccurred at various times during the plan development. The following chapters will. focus upon specific tasks undertaken by NWDA to illustrate the manner in which these areas of confusion influenced both the planning process and the roles assumed by Staff and NWDA. 


\section{Footnotes}

1 "Proposed Policy Statement on District Planning," Portland City Planning Comnission, April 14, 1971. 


\section{SUB-COMMITTEE WORK \\ AND NEIGHBORHOOD MEETINGS}

\section{Introduction}

The previous chapter indicated that both NWDA and Staff held varying ideas as to the role each was to assume in developing a neighborhood plan. In general, both NWDA and Staff agreed that NWDA was to provide something called "citizen input" for the plan. They broadly defined this "input" as consisting of citizen attitudes regarding the neighborhood and its future which were to be incorporated into the comprehensive plan. This chapter will focus upon several tasks undertaken by the NWDA to provide "citizen input" for the plan and the ways in which NWDA and Staff defined their roles and the issues which developed as they attempted to clarify their roles and specific responsibilities.

Early in the planning process, NWDA formed a Planning Committee composed of a chairman, sub-committee chairmen, and other appointed individuals, to provide for and organize the citizen input for the comprehensive plan. Essentially, the duties of the Planning Committee were to conduct studies and otherwise provide the information regarding citizen needs and attitudes necessary for the Staff to develop the plan, and to act as a liaison group between Staff and the NWDA. Sub-committees were appointed to study and involve citizens in formulating neighborhood goals and objectives for the areas of housing, land use and zoning, traffic, business, and social and economic factors.

In December of 1970, Staff distributed a paper describing the sequence of tasks to be completed by both Staff and NWDA in developing the district plan. Staff described the work sequence in terms of the following tasks: ${ }^{1}$

1. Survey available information; i.e., census data, reports on Northwest Portland, etc.

2. Develop preliminary attitudes and hypotheses (to be done by sub-committees). Citizen Review (attitudes and hypotheses to be discussed with small groups of citizens). 
3. Formulate and conduct in-depth surveys (from citizen group discussions and available information a series of studies are designed and conducted to gain fresh knowledge about social and economic forces and physical conditions in Northwest Portland)

4. Compile and coordinate findings.

5. Define alternative goals, objectives and implementation strategies. Citizen Review (citizens to select alternatives worthy of further study)

6. Examine alternatives in detall (working sub-committees and planning staff examine feasibility, costs, and benefits of each alternative selected by citizens)

Citizen Review (citizens select final alternatives)

7. Develop final plans and programs (all selected planning alternatives are integrated into a final document ready for citizen, Planning Commission and Council approval)

According to this planning sequence adopted by NWDA and Staff, NWDA assumed responsibility for organizing and providing for citizen input in three areas. First, the sub-committees were to study and involve citizens in developing a set of preliminary attitudes and hypotheses about the district which could be tested in a survey. For example, the land use and zoning subcommittee would be open to citizens interested in issues involving land use and zoning in the district. The sub-committee would provide for open meetings to discuss these issues with area residents and then utilize the information and attitudes expressed by the citizens to formulate goals for land use and zoning which would be incorporated into a neighborhood survey. This survey would seek to obtain further citizen reaction to possible land uses for the district.

Second, the NWDA was to assist the Staff in preparing and conducting the neighborhood survey. NWDA would provide a set of tentative planning goals and objectives for the district through the use of its sub-committees as described previously. Then NWDA would enlist the support of citizens to actually conduct the survey of the neighborhood. 
Third, the NWDA was to organize and coordinate neighborhood meetings which would provide for direct citizen input for the plan.

Staff's role in this process was technical. They were to design the survey using the information gathered by the citizens; compile the information from the survey; formulate alternatives regarding possible planning for the neighborhood; and draft the final plans and documents from the results of the survey and other sources of citizen input.

Both Staff and NWDA saw the neighborhood survey as their main source of citizen input for the comprehensive plan. However, the City Council did not release the funds for the survey. This produced confusion in the NWDA as they were forced to plan for the neighborhood without knowing for whom, exactly, they were planning. The planning had to be continued without the survey, thus leaving the work done by the sub-committees and the neighborhood review meetings as the main sources of citizen input.

Since the use of the sub-committees and the neighborhood meetings were designated as the means by which NWDA was to provide citizen input for the plan, they will be used as examples of how confusion over what specifically was expected by citizen participation and the resulting confusion over responsibility for tasks influenced joint NWDA-Staff planning.

\section{Clarification of Roles.}

In June of 1971 , Staff prepared a revised schedule of tasks to be completed by the PCPC Staff and NWDA in developing the comprehensive plan without data from the main survey. ${ }^{2}$ The tasks to be completed by NWDA were four-fold. First, they were to develop a set of tentative neighborhood goals and objectives derived from the sub-committee reports. Second, the NWDA was to organize and conduct neighborhood meetings to discuss these tentative goals and objectives 
during the summer. Third, in the fall they were to provide for a sub-area review of alternative plans for the neighborhood. Finally, they were to distribute the preliminary plan to the neighborhood.

Staff was to provide technical assistance in preparing the social services report; developing alternative goals and objectives for the neighborhood based upon input from the neighborhood meetings and provide illustrative plans expressing these goals and objectives; prepare the final draft and printing of goals and objectives; and prepare the preliminary plans.

The relationship between Staff and NWDA then was defined as a co-partnership, with Staff being responsible for technical input and NWDA being responsible for citizen input for the plan.

\section{Use of Sub-Committees in Providing Citizen Input}

When the sub-committees were reorganized in November of 1970, Staff and NWDA agreed that the sub-committees would each use their specific issue, such as housing, business, etc., to involve citizens in the planning for the neighborhood. Staff at this time assumed a leadership role by preparing a brief list of issues to which each sub-committee might want to address itself in studying its particular area of interest. The sub-comittees were to present a preliminary statement of attitudes and hypotheses for the neighborhood in January of 1971. When the survey which was to test these hypotheses was cancelled, the sub-committees were to continue to work at formulating goals and objectives for their respective area of interest. As summer approached and the NWDA needed information to present to the neighborhood residents at the proposed summer meetings, one of the NWDA board members requested staff to prepare a statement of tentative goals and objectives for each of the sub-comnittees, as the sub-committees had not yet prepared these. Staff, using the general 
consensus regarding neighborhood goals and objectives expressed by NWDA members at planning committee meetings, then assumed responsibility for formulating tentative goals and objectives for the Plan. They presented these goals and objectives at the June 24, 1971, meeting of the Planning Committee. Some of the chairmen felt that Staff had ignored the original sub-committee hypotheses and that this was an attempt by Staff to force their ideas for the neighborhood upon NWDA. However, although revised several times, these goals and objectives were eventually accepted by NWDA for the Comprehensive Plan. This was an example of Staff assuming responsibility for a task assigned to the NWDA. Although Staff was requested to do this, it produced some discord within NWDA as some members were skeptical of Staff and their motives for writing goals and objectives for the district.

With respect to the work done by the sub-committees throughout the planning process, both Staff and the NWDA felt that the sub-committees had neither involved the citizens nor thoroughly studied the issues for which they were responsible. Three main reasons were given for this failure. First, planning and the formulation of goals and objectives for a plan is an abstract concept and difficult for the average citizen to grasp. Although NWDA accepted the responsibility for formulating goals and objectives for the district, they did not have the needed expertise. Second1y, all work done by the NWDA was voluntary. Thus, sub-committee chairmen often found it more productive to formulate goals and objectives themselves or make decisions themselves, rather than spend their limited time in organizing other citizens to provide this input. Also, since Staff was paid and NWDA was not, NWDA members would at times neglect work, assuming that Staff could help out. The Business Sub-committee and the Social Services Sub-committee exemplify some of these problems regarding NWDA responsibility for citizen input. 


\section{$-32-\quad$.}

Business Sub-Committee

The Business Sub-comnittee was to obtain input from business in the neighborhood and test their reaction to the plan. Reasons given by the chairman of the Business Sub-committee for its failure to effectively involve businesses in the planning were varied. Essentially, he felt that the small businesses which actually provide services for area residents, were represented in the NWDA as their survival depended upon the patronage of area residents. These sma11 businesses had a vested interest in the neighborhood and its future. Other businesses not so dependent upon the neighborhood felt that the NWDA was essentially a residents' association and, hence, was advocating interests in conflict with those of business. Therefore, they did not involve themselves in the planning process. The larger businesses in the neighborhood had traditionally gone directly to the Planning Commission or City Hall and ignored NWDA as a source of authority in planning for the neighborhood. Finally, the effort that would be involved to overcome this resistance on the part of business and conduct surveys to test their reaction to the plan was thought by the Business Sub-committee to be more than could be expected from volunteers.

In the end, Staff was forced to do a survey of businesses in the area to gain their reaction to the plan. After the neighborhood had prepared its plan for submission to City Council, business organized and hired a planner to develop an alternate plan, which they felt would be more favorable to business interests.

In the functioning of the Business Sub-committee, NWDA accepted the responsibility of providing for area business representation in the plan but they had neither the time nor the perceived authority to effectively provide for this input. Neit her Staff not NWDA attempted to renegotiate and 
specifically redefine steps necessary to provide business participation in planning. Staff assumed some of the responsibility but the involvement of business was minimal in developing the olan.

\section{Soc ial Services Sub-Committee}

The Social Services Sub-committee was appointed at the same time as the other sub-committees. However, the chairman of the sub-committee moved from the neighborhood before the committee met. Staff felt that a statement of social needs should be included in the district plan. Since they were not social planners, Staff felt that the preparing of this statement should be the responsibility of the NWDA. The NWDA and district residents also expressed the need for improved social services. Nevertheless, a new chairman for the Social Services Sub-committee was not appointed and as a result the committee never met. When the time was nearing for the completion of the Comprehensive Plan, Staff contacted NWDA to ask that a new chairman be appointed. Staff also called some initial meetings to prepare a statement on social needs of the neighborhood. A Staff person from the Tri-County Community Council attended these meetings to provide some direction for the plan, but the committee as a whole was not prepared to develop a social plan. Staff finally was able to hire a soctal planner for six weeks to develop a statement of social needs and possible social planning for the district. He relied upon agency people who had worked In NWDA and upon the findings of the summer meetings to develop a statement of social goals and objectives. He then formulated a tentative statement of social goals and objectives for the neighborhood which was accepted by the new Social Service Sub-committee and incorporated into the plan by Staff.

The Social Service Sub-comnittee is an example of how lack of expertise in social planning on the part of both Staff and NWDA caused the issue of 
social services for the neighborhood to be neglected until the end of the planning process. Social planning is an abstract concept and more than the average citizen can handle without professional assistance. The time involved in contacting citizens, agencies, and social services delivery systems in the area is also more than the average volunteer has the time to do. NWDA did accept responsibility for developing a Social Service report. However, because of their lack of expertise in social planning and lack of Staff support in this area, this issue was dropped until the end, where, as with the Business Subcommittee, Staff assumed the responsibility of providing for a Social Service report for the plan.

\section{Neighborhood Meetings}

The second source of citizen participation in the plan was to be a series of neighborhood meetings to be held with groups of area residents. As the summer approached, Staff reminded the NWDA of their responsibility for conducting the summer meetings and the amount of effort that would be involved in preparing for them. It became obvious to some of the NWDA board members, since many of the NWDA planning committee board members were out of town for the summer months, that one person was needed to organize and coordinate the meetings. NWDA assumed their role as agreed and obtained some money donations to hire a staff person for the summer to organize the meetings. This staff person met with both PCPC Staff and NWDA to outline a work schedule for the summer.

Basically, the goal was to hold fifty small group meetings during the summer with the residents of various sub-areas of the neighborhood. Teams composed of a discussion leader and a recorder, supplied by NWDA, would conduct these meetings. Rather than present the tentative list of goals and objectives which had been prepared by the Staff, the leaders of the meetings were to ask 
general questions which would elicit responses pertaining to the areas covered In the statement of goals and objectives.

The NWDA organizer then scheduled a series of meetings at variovs locations in the neighborhood and notified residents in the area of meeting times and locations. He also obtained the names of NWDA members who would form the teams and scheduled them along with the meetings. He briefed these teams on what they were to do and how they were to fill out their report forms. He later compiled the results of the meetings.

In doing this work, the NWDA community organizer received assistance from three NWDA women who knew the area and could provide him with much of the information that he needed. NWDA as a whole did not offer him much support in preparing for the meetings.

The goal of the fifty summer meetings was met and both Staff and NWDA felt that the program, in general, had been successful. They attributed the success of these meetings to the fact that there was a full-time staff person doing the organizing, setting up a work schedule, and giving NWDA a specific direction. These meetings provided NWDA volunteers with a sense of accomplishment because they were assigned specific tasks to complete and the result was observable.

In general, the NWDA Staff person not only provided some expertise in organizing, he also had the time to devote himself specifically to the job, and devise a work schedule to maximize the use of volunteer time.

NWDA and staff felt that meetings such as these should have been carried on during the entire planning process; however, there was no one to organize them. NWDA believed that the effort involved in organizing these meetings required a full-time staff person and they did not have the funds available for 
this. Organizing citizen meetings was seen by Staff as outside their role as technical advisors to NWDA.

The results of these meetings were used to refine the statement of goals and objectives for the neighborhood. Three alternative plans were developed for the neighborhood and in the fall staff reminded NWDA of their responsibility to organize sub-area meetings to review the plans before one plan was developed and presented to City Council. At this time a staff person was not hired to organize the meetings. Instead, two of the women who had assisted with the summer meetings contacted the persons who had attended the summer meetings to inform them of the new meetings. Three meetings were held with a total of about 80 persons attending. In order to obtain more citizen representation, notices were sent to everyone on the NWDA mailing list (about 500) and a fourth meeting with about 100 persons in attendance was held. Staff presented the three alternative plans and asked for a vote by those in attendance as to their preference. The results of this meeting were used to develop the final neighborhood plan.

These meetings were not as large as the summer meetings but the women organizing them were able to use the names of the persons contacted during the summer for these follow-up meetings.

Summary ,

The NWDA accepted a co-partnership role with Staff which conferred upon the NWDA responsibility for citizen involvement in the planning process. The two main vehicles agreed upon by Staff and NWDA for this citizen involvement were the sub-committees and the neighborhood review meetings. Staff listed general tasks to be completed by the NWDA and deadlines to be met. It was then up to the NWDA to plan for and accomplish these tasks. In the cases 
of both the Business Sub-committee and the Social Service Sub-committee, the NWDA accepted the responsibility for providing citizen input through the use of these sub-committees to study and formulate a statement of neighborhood goals and objectives in each area of interest. However, the expertise and time required to thoroughly study these issues, involve citizens and then formulate goals and objectives were more than the sub-committee chairmen could offer. In addition, in the case of the Business Sub-committee, the NWDA did not have the perceived authority to actively involve business in the planning. In the case of the Social Services Sub-committee, they did not have the needed expertise in social planning.

When these sub-committees were failing, no formal attempt was made by NWDA or Staff to specifically define tasks to be done by each of the subcommittees, evaluate the feasibility of accomplishing their tasks and then redefining the roles of NWDA in planning for business and social service needs for the district. Staff ended up filling in for the work which the NWDA failed to complete.

In organizing neighborhood meetings, NWDA hired a staff person of its own. The Staff organizer was able to plan for and schedule the meetings, assign specific jobs to NWDA members and then coordinate the meetings and tabulate the results. The result was that the responsibility and leadership for the task of organizing neighborhood meetings was given to one person who could devote himself completely to the task. By partializing the work that needed to be done, he was able to maximize the work that could be accomplished by volunteers and the volunteers, in turn, received the satisfaction of completing a specific task and seeing the results of their work. Both NWDA and Staff considered these meetings as successful in achieving the citizen input that was needed for the plan. 
In genera1, where NWDA possessed the expertise and resources needed to involve citizens, they fulfilled their responsibility as co-partners with Staff in planning for the district. However, in the use of sub-committees, neither expertise, authority, nor resources in terms of money and time were available to NWDA. Therefore, although they accepted responsibility for involving citizens in formulating goals and objectives for the district, they were unsuccessful in fulfilling these tasks. Staff assumed responsibility for these tasks in the end. 


\section{Footnotes}

1 Organization Chart for Northwest Comprehensive Plan, 12-8-70, P.C.P.C.

2 "Northwest Comptehensive Plan," Work Program, 6-23-71. 


\section{FREEWAY ISSUE}

\section{Introduction}

In 1965 plans were finalized concerning a freeway that would be placed through the Northwest part of Portland, to run along the northern boundary. This freeway (I-505) would be connected to another major freeway (I-405) by a new proposed bridge. NWDA took an interest in this proposal, since both freeways would influence their neighborhood.

This chapter will focus upon several tasks undertaken by the NWDA and PCPC Staff in their efforts to deal with the proposed freeway. In identifying the relationship NWDA had with Staff around the freeway issue, it became clear that certain areas of confusion developed. NWDA was not always clear as to the role Staff was playing, nor of Staff's expectation for NWDA. The roles of both PCPC Staff and NWDA varied as they encountered different tasks, but confusion centered primarily around NWDA's expectation of Staff taking a more political role than they had taken in the sub-committee work and neighborhood meetings.

The initial relationship between NWDA and some PCPC Staff occurred when the State Highway Commission contracted PCPC and their staff to do a study of the possibilities for multiple uses and joint development of the proposed freeway through Northwest Portland. This report was later called the Blue Book Report. PCPC Staff were asked to ascertain the type of freeway that would be most acceptable to residents and landowners in the district. They assumed the leadership role, in this initial contact by presenting the alternative plans to NWDA. Members of PCPC Staff, different from those staff members later to work with NWDA on the Comprehensive Plan, asked NWDA to hold a public meeting, March 17, 1970, to present the alternative plans for freeway elevation and alignment. In this initial relationship, Staff viewed the role 
of NWDA as representing residential interests, and also as a vehicle to involve other Northwest residents.

NWDA publicized the meeting, inviting residents as well as NWDA members. One-hundred people attended the meeting to act as representatives of the area. At this particular meeting Staff presented the six freeway alternatives prepared by PCPC Staff and the State Highway Commission. They used their professional expertise to develop a comparative analysis of the advantages and disadvantages of each plan, which they presented at the meeting. This placed PCPC Staff in a technician's role. NWDA voted on their choice of freeway alignment. This cholce had an underlying implication important in later freeway discussions. Since NWDA did not oppose the freeway at this time, it implied they had accepted the proposed corridor on the northern boundary of their district. This contact between NWDA and PCPC Staff can be viewed as successful since it satisfied the expectations of both parties.

In this beginning contact with Northwest Portland, Staff took the responsibility of contacting non-resident interest groups. For example, they held a meeting with business and industrial interests in the area to discuss freeway alternatives. However, later on when NWDA was working with new PCPC Staff to develop the Comprehensive Plan, NWDA was expected to see that business and other interests were involved in the plan.

Staff utilized the opinions received from the residents, business and Industry to write the Blue Book Report. This report was to be presented to City Council for approval before sending it, officlally, to the State Highway Commission.

By this time the two staff members, who were involved in planning with NWDA, were already working with them. In February, 1971 these staff, at the 
request of the Planning Department, presented to NWDA the possible uses of land along the freeway corridors. Staff assumed the role of technician in this relationship, while expecting NWDA to take the political role of voting on the plans presented. NWDA members were in agreement with Staff's report but felt they could present some additional points to City Council to insure the livability of their neighborhood. These four points included:

(1) Supporting the concept of multiple uses for the corridor.

(2) The same number of residential units taken out by the freeway should be replaced in Northwest Portland.

(3) The families who are relocated by the freeway should be permitted to remain in Northwest Portland and replacement housing should be supplied.

(4) The freeway traffic, both coming on and off, should be rerouted to the north side of the freeway, that NWDA would not consider any north-south streets as arterials but rather as neighborhood commercial streets.

A1so, NWDA voted to adopt the objectives of PCPC concerning the freeway as objectives of NWDA. NWDA did not belleve they could legally oppose the freeway at this time.

NWDA in The Leadership Role

NWDA held a series of meetings discussing the four points and their legal implications. They decided that a social survey of the corridor might be used to back their positions. NWDA took the initiative in contacting PCPC and requesting that the social survey be completed. PCPC allotted funds for a paid staff person to act as technician, and NWDA volunteered the use of their name and volunteer interviewers for the survey. NWDA decided that some of their members and the paid PCPC staff person would train these volunteers. When completed, this social survey successfully gave evidence that areas in transition 
from residential to industrial, and those affected by freeway corridors, were in danger of chronic social 111s. ${ }^{1}$ NWDA hoped that their four points would be adopted by the Highway Commission to combat these social ills.

Both NWDA and Staff considered the survey a success. This success may be attributed in part to the degree of certainty NWDA had about their goals. They took the leadership role and assigned the role of technician, with specific duties, to the staff. Both NWDA and Staff were certain of their own role and the tasks they were to accomplish in the survey.

\section{Evolving Conflict in Expectations}

At the City Council hearing of the PCPC Staff Blue Book Report, NWDA gave an organized presentation of their four points. The four points were not part of the Planning Commission's report. The Staff did not feel that they should take an official stand for or against NWDA's positions. 2 staff saw themselves, at this point, as technicians and did not consider themselves as advocates for NWDA. A question of Staff advocacy developed around this issue since NWDA hoped that the City Council and PCPC Staff would act as an advocate for their four points. However, their opinions were not adequately communicated at the hearing. City Council voted that the Blue Book Report prepared by PCPC Staff and an extract from presentations at the hearing be forwarded to the State Highway Commission for its use in planning the freeway corridor. A PCPC Staff, not working with NWDA, summarized the presentation and sent it to the Highway Commission. The citizens' positions were not incorporated into the City Council position. A City Commissioner read the proposal, felt the citizen suggestions had been "too watered down," and attempted to rewrite the letter; however, the first letter was sent before the second could be submitted. In the submitted 


$$
-44-
$$

letter the NWDA's four points were not actually written as part of the Planning Commission's report.

NWDA members felt that the City Council was greatly impressed by the orderly and well-presented position of NWDA regarding their four points for the freeway. They also believed that Staff suggested to the Highway Commission that they accept these four points. They thought that their four points were fundamentally a part of PCPC's proposal and that City Council and PCPC Staff were supporting NWDA's position. 3 Actually, PCPC did not feel it was their position to take a stand on NWDA's proposal.

Later, when the State Highway Commission did not indicate acceptance of NWDA's four points, NWDA believed they had been disregarded. NWDA felt jilted, that PCPC had not presented their four points in a forceful enough manner. They expected PCPC Staff to see that their four points would be incorporated into the PCPC plan presented to the Highway Commission. Staff had to reiterate that this had not been their function.

\section{Development of NWDA-WHNA Joint Proposal}

About this time WHNA (Willamette Heights Neighborhood Association), another neighborhood group, became concerned that the Highway Commission was not taking into consideration the points they had presented at the previous City Council hearing. At that hearing Willamette Heights had proposed that the Highway Commission follow the conditions of a federal environmental impact act. They questioned whether the environmental act was being violated in the freeway construction. WHNA's president initiated contact with NWDA over this concern. NWDA members met with WHNA to explore common concerns over the freeway corridor. At the meeting a joint proposal was suggested, although this had not been the 
original purpose of the meeting. Basically the joint proposal included; previous positions on the I-505 Freeway Project taken by the NWDA and WHNA; (2) a comparison of the performance of the Oregon State Highway Commission to the requirements of the Federal Environmental guidelines; and (3) conclusions and recommendations. PCPC Staff were not involved in this proposal writing. The NWDA president approached a lawyer to assess the feasibility of some kind of court action. The lawyer indicated that there was a good chance the views could be put forth forcefully in litigation based upon legal precedent. He suggested that they halt freeway construction by going to court on the basis that the Highway Department had not upheld Federal Environmental guidelines. When the proposal and the lawyer's suggestions were presented to NWDA board members and planning committee, there was much disagreement. Some members felt that it was not the duty of the committee that talked with WHNA to develop a joint proposal in the first place. ${ }^{4}$

PCPC Staff, informally, felt the fight would be idealistic and the Highway Commission was now beginning to act upon NWDA's four points. They were afraid that NWDA would be putting all of their energy into one issue by trying to stop the freeway construction for an environmental impact study and lose Highway Commission consideration of their previous four points. Staff felt sympathy for WHNA proposal but did not feel NWDA could help. They saw the push for a change in alternate routes to the freeway as coming too late. It was stressed that the summer neighborhood meetings showed that the citizens would not be willing to remain in doubt about the freeway issue for much longer.

Some NWDA members were displeased with PCPC Staff because they felt their proposals had not been backed by Staff when presented to the Highway Commission by PCPC. Staff had to repeat that it had not been PCPC's role to take a political 
stand on this issue. Also, one of the City Commissioners had attempted to present their four points more forcefully, but the letter had not been written in time to send it to the State Highway Commission. This developing dissatification of NWDA with PCPC may have had some effect on discounting Staff's view against fighting the new freeway.

Some NWDA members felt that the best way to fight the freeway was still through their original four points. Furthermore, attempting to stop the freeway construction in court proceedings changed NWDA's official position. Other members felt that if an environmental impact study was completed it could include NWDA's original four points. They said that NWDA had a right to change positions, and it was a question of which tool could be used to get the best results for Northwest Portland.

\section{Planning Staff Role}

PCPC Staff had no formal role in the process of deciding which course of action should be taken against the freeway. Informally they told NWDA that nothing could be done to change the freeway route and that NWDA would be wasting its time.

Throughout NWDA's involvement with the freeway issue, Staff, without official request from NWDA, informed NWDA of State Highway Commission decisions. Staff took the initiative of going to the state capitol and having some contact with the Highway Commission. Staff was very helpful to NWDA in finding out when public hearings would be held, and decisions made about freeway development. Occasionally NWDA was dissatisfied that they were not notified about important dates, but it was not the Planning Staff's duty to assume this role. NWDA members frequently spoke of the importance of having someone inform them of developing decisions effecting the neighborhood. Staff did not always feel 
they had the time to find out what was necessary, and NWDA did not feel that they could take on this task without a paid staff person. Neither PCPC Staff nor NWDA saw informing each other of important meetings and issues as their responsibility. PCPC Staff, as a result, was forced to take the initiative.

\section{The Freeway Hearing}

Plaintiffs in the suit against the State Highway Commission over the proposed routing of I-505 were NWDA and WHNA. They contended that Highway officials failed to hold public hearings and violated federal environmental requirements in failing to study alternate routes. They also contended that west bound off ramps under construction from a new bridge had already predetermined the freeway corridor. Highway officials maintained that corridor hearings were held in 1964; that environmental impact studies were presently underway; that off ramps,

actually part of another new freeway, did not predetermine the freeway corridor. 5

Once NWDA entered the suit, Staff informally supported NWDA's position. This pending court decision was viewed by both Staff and NWDA as vital for the continued motivation of NWDA members and Northwest citizens. Both felt citizens needed tangible successes to remain active in the planning. Both saw the final decision as important because it would effect the proposed comprehensive plan for Northwest Portland.

\section{Development of I-505 Section of the Comprehensive P1an}

No special committee was established to write the goals and objectives concerning the freeway to be part of the Comprehensive Plan. In February, 1971, one Staff member took the initiative to write an introductory statement for the preliminary Staff paper of Northwest Goals and Objectives to be used as a guide for the NWDA working sub-committees. He included NWDA's four points in this 
statement. Although Staff took the initiative in writing this section, no one was specifically designated to review what was written. As a result, the revised edition of Goals and Objectives written in November of 1971, was still the original Staff writing. These were reviewed, with possible corrections and additions, by the NWDA sub-committees at a planning retreat. None were made.

Planning Staff questioned the wording of the Goals and Objectives for this section. Since the Highway Commission had been taken to court, Staff questioned whether the four points should be changed to read "if" the corridor is chosen at the hearing. Planning Staff's question was not answered by NWDA at the retreat. This is one more example of how Staff were forced to assume an extra task because no one from NWDA had been assigned the responsibility.

\section{Summary}

- Initial contact between Staff and NWDA was with staff different from those later involved in the comprehensive plan development and centered around the presentation of alternate alignment plans for a future freeway (I-505 and I-405). In this first contact, Planning Staff assumed the leadership role in contacting NWDA and in presenting the plans. In addition, Staff took the responsibility of contacting business and industrial interests to gain further input. Staff viewed NWDA as representative of residents in the neighborhood. This NWDA role was different from their later role of gathering suggestions from other Northwest residents, as well as from business and industry. This initial relationship met both parties' expectations since they both functioned in their designated roles.

Planning Staff again initiated contact with NWDA concerning discussion of possible land uses for freeway corridors. Out of this contact grew NWDA's four points concerning the freeway. 
Planning Staff and NWDA worked together to do a study of the residents who would be affected by the future freeway corridors. NWDA was able to successfully accomplish their goal of conducting a social survey when they toot. the leadership role; were clear on what they wanted accomplished; and defined the Planning Staff's role as technician and PCPC's role as financier.

When NWDA presented their four points to City Council, they expected that they would be incorporated in the proposal to the Highway Commission. However, NWDA did not present their four points to City Council in this manner. When the four points were not included as part of PCPC's report, since Staff felt it was not their job to take a political stand, NWDA felt jilted. When Willamette Heights Neighborhood Association contacted NWDA concerning the Highway Commission's activities, NWDA leadership had just changed hands. Members were disillusioned with PCPC not presenting their four points strongly enough, and the possibility that the Highway Commission would not act on their points was becoming more eminent. The WHNA and NWDA meeting resulted in the writing of a joint proposal which produced much conflict within the NWDA. The final decision was that NWDA would continue with the hearing, in spite of Staff expressing concern over their success. This brings out the question of staff loyalty. If NWDA had divided over this conflict with which group would Staff continue their relationship?

The role of Staff at this time was to inform NWDA of relevant Highway Commission activity. This was not Staff's responsibility and was not always accomplished satisfactorily, since Staff did not have the time nor felt it was their responsibility to find out what was happening for NWDA. This is one role that could be assumed more effectively by a paid Staff person working for the neighborhood association. 
Planning Staff wrote the portion of the Comprehensive Plan concerning the freeway from the four points accepted by the NWDA and general feelings expressed at the meetings. No one was designated to review the Goals and objectives and no corrections or additions to them were made by NWDA. This is another example of how Staff took the initiative when tasks were not clearly designated to NWDA.

In the development of the freeway issue it can be seen that roles were not always clearly defined as to who was to take the initiative. As a result, NWDA members and/or Staff were not always satisfied with the results. Tasks were not always successfully completed. A question of Staff advocacy arose in the Blue Book report issue. Most satisfactory results concerning the social survey completed by both NWDA and Staff occurred when NWDA took the leadership role and clearly communicated their expectation for Staff. 
1 Paul Pintarich, "Youths Add Pep to NW Portland," The Oregonian, February 10, 1971.

The report that developed was later used, in part, in the interim reports prepared by Staff ("A Study of Conditions, Problems and Potentials" and "A Study of Social Factors"), and was presented to citizens, City Council and PCPC to familiarize them to conditions of Northwest Portland in relation to the coming Comprehensive Plan. It was also used in writing the Comprehensive Plan.

2 At this same hearing another neighborhood association, Willamette Heights Neighborhood Association (WHNA), presented their position on the freeway corridor.

(1) An impact study for a proposed Environmental Statement.

(2) Participation in decision-making process by citizens effected by the freeway.

(3) Stop removal of residents pending an adequate consideration of alternate transportation systems.

WHNA, as Portland residents, also had the right to give suggestions in regards to the Blue Book report. They too had a right to expect City Council to place their suggestions in the report to the Highway Commission.

3 NWDA minutes, 3-16-71.

4 About this time their was a change in leadership within NWDA.

5 The Oregonian, October 18, 1971.

Results of the hearing were in favor of NWDA and WHNA and stipulated further environmental impact studies. This does not mean, however, that the freeway corridor will be moved. 


\section{Introduction}

Throughout the development of the comprehensive plan for Northwest Portland, NWDA was concerned with Good Samaritan Yospital's major expansion proposal and how it would effect the "livability" of the area." In viewing the Good Samaritan issue, the question of Staff loyalty, as well as how non-resident interest groups can become involved in community planning was exemplified. The position Staff assumed was different from the position centering around the freeway issue. Their actual role became more political. PCPC Staff began to promote the comprehensive plan.

\section{Rising Question of Staff Accountability}

Staff saw their role in the neighborhood to include planning for resident as well as non-resident interests within Northwest Portland. The question of Staff accountability arose in April of 1971 when Staff attempted to assume a broker role between NWDA and a non-resident interest group, Good Samaritan had applied for a conditional land use to expand their parking lot, which would remove two single-family homes. Staff notified the NWDA zoning sub-committee about this expansion. In addition, Staff spoke with Good Samaritan administration in an effort to "build some bridges" between the two interest groups. Meanwhile, NWDA made an attempt at fighting the hospital's application. As a result, Good Samaritan saw Staff as an advocate for NWDA and questioned the validity of a city planning staff assuming this role. ${ }^{2}$ It became clear that Staff must redefine their role, especially for Good Samaritan Hospital. One of the Staff members met with Good Samaritan administrators in an attempt to redefine their position. Staff stressed they were working to combine the interests of the entire neighborhood. They saw their responsibility to Northwest Portland as a whole. Sometimes this meant they were assuming an NWDA 
position.' This position taken by Staff is in contradiction to their essentially technical, non-political role previously discussed in the freeway issue. Staff also emphasized the value of Good Samaritan involvement in the comprehensive planning process with NWDA. They suggested Good Samaritan representatives attend NWDA meetings to better understand what was happening. As a result of this meeting, Staff's role became more clear for Good Samaritan.

In May, when Staff was requesting a continuation of funding for the plan, a Good Samaritan administrator wrote to the mayor supporting the continuation of Staff funding. Good Samaritan then saw Staff as working for the city, instead of merely an advocate of NWDA. ${ }^{3}$ They felt staff had more power to effect Good Samaritan Hospital's ability to expand.

\section{NWDA Involvement with Good Samaritan Hospital}

NWDA made an effort to involve Good Samaritan in a more active role in planning. In May of 1971 the NWDA president recommended that plans be made to include the executive board of Good Samaritan Hospital in an exchange of ideas relative to the objectives of the hospital and its expansion plans. ${ }^{4}$ At this time there was much distrust between Good Samaritan Hospital and NWDA. Some of this distrust can be attributed to the poor reception of Good Samaritan at the 1969 neighborhood meeting when they presented their expansion plan. In spite of this distrust, through the efforts of NWDA and suggestions by Planning Staff, two executive members of NWDA and two hospital administrators met prior to the larger NWDA board meeting to formulate an agenda. At the board meeting each group presented their goals for the neighborhood. After this meeting, Good Samaritan often had a representative at NWDA meetings. 
Staff's Role of Informing Good Samaritan Hospital

Good Samaritan Hospital and other non-residential interest groups in Northwest Portland began to see PCPC Staff as instruments for change rather than as working with NWDA for comprehensive plan development. They did not see NWDA as possessing the political power to create a comprehensive plan that would ever be used by the city.

By late summer of 1971 Staff had completed three alternative plans for Northwest Portland. The plans were presented to NWDA, as well as to other groups in the neighborhood to ascertain preferences. Staff became concerned because of the lack of feedback from Good Samaritan Hospital; however, they did not see it as their role to plan a meeting with the hospital. At this same time Good Samaritan was wondering what the PCPC Staff was proposing for the neighborhood. A representative from Good Samaritan, involved in the neighborhood, became aware of both parties' concerns and planned a meeting in which Staff could present their alternative plans. Good Samaritan asked that NWDA not be invited. In this case Good Samaritan did not view NWDA as a power source, but preferred direct contact with Staff.

The meeting was held and Good Samaritan expressed approval of two plans. Staff hoped that by involving Good Samaritan Hospital in the planning stage they could avoid confrontation with Good Samaritan when the final plan was presented to City Council. Staff was aware of the importance of avoiding conflict within the district between resident and non-resident interests once the plan was completed. If City Council felt that the comprehensive plan was not a combined effort of the total community they might have doubts about accepting it. 
Staff took the responsibility of meeting with Good Samaritan Hospital to gain their suggestions, even though it was an NWDA responsibility. NWDA had more difficulty obtaining Good Samaritan involvement because of the distrust that had to be overcome by both Good Samaritan and NWDA.

Development of the Good Samaritan Hospital Section of the Comprehensive Plan

As with the freeway issue, no special committee was appointed to write goals and objectives concerning Good Samaritan Hospital. Staff wrote the original section on Goals and Objectives for Good Samaritan. In November, 1971, the revised edition of NWDA Goals and Objectives for Good Samaritan was still the original Staff work. When presented to the NWDA Executive Board for suggestions there was little comment. When NWDA did not assume the initiative for writing this section PCPC Staff assumed the responsibility.

NWDA and Good Samaritan Hospital in a Working Relationship

Good Samaritan became more involved in NWDA when they began to realize how NWDA could benefit the hospital. In the summer of 1971 , Good Samaritan had been notified that their grant had been turned down by HUD. At this time Staff had begun to consider possible alternatives for implementing the comprehensive plan and were talking with PDC about the possibility of rehabilitation funds for the Northwest. It appeared that NWDA would obtain an NDP grant since they had a clear objective on land use. If this occurred, NWDA would have considerable control over the expenditure of NDP funds. This contributed to the increased interest of Good Samaritan in NWDA. At a November meeting Good Samaritan administrators presented to the NWDA board their goal of providing broader services for the community. Their five-year plan had been reduced to the closing for one block of a side street and the narrowing of another. 
Their 15-year plan included expanding the hospital upward rather than using more land area. The plan met favorably with NWDA and Staff. 6

The compromise that Good Samaritan was able to achieve with NWDA can be attributed to the efforts by Staff to involve the two interest groups in planning together and NWDA's attempt at involving Good Samaritan in May, 1971. Good Samaritan's inability to obtain HUD funding and NWDA's opportunity to obtain an NDP grant for the area also contributed to the reconciliation of differences between the two interest groups. At the completion of the first draft of the comprehensive plan, both NWDA and Good Samaritan Hospital had entered a more trusting, therefore, more satisfactory relationship.

\section{Summary}

The issue of Good Samaritan Hospital illustrates the problem of defining S.taff constituency in planning for Northwest Portland. Because of Staff's involvement with NWDA, Good Samaritan thought that PCPC Staff was acting as an advocate for NWDA and essentially for residential interests. They questioned the validity of a city planning agency doing advocacy planning. At this point Staff redefined their role as involving non-residential as well as residential interests in planning. Some of the confusion could have been eliminated if Staff had originally defined its constituency more clearly and if NWDA had fulfilled their role of gaining suggestions from all interests within Northwest Portland. Staff clarification of their role to Good Samaritan created more Involvement between NWDA and Good Samaritan in the development of the plan. As the NWDA-Good Samaritan Hospital relationship developed, Good Samaritan conceded to expand their hospital upward, rather than using more land. This Indicated that they were considering the interests of the rest of the neighborhood. 
Once the comprehensive plan was near completion Staff began to assume a more political role. They became concerned about support from non-resident interests, as well as resident interests. They attempted to avoid inner nelghborhood conflict when presenting the plan for approval by City Council.

Good Samaritan is an example of how non-residential interests still want to use traditional channels for change. Good Samaritan saw Staff and the Planning Commission as a way to accomplish change. Staff had to point out that in working with NWDA, Good Samaritan could insure that their interests were included in the plan. Good.Samaritan became more involved with NWDA when they could see that possible involvement with NWDA might benefit them. To evoke active participation from interest groups each must gain some benefit for their involvement. Good Samaritan had to see what gain could be made for them by becoming involved in district planning. 


\section{Footnotes}

1 For example, NWDA was concerned with what would happen to displaced residents due to this expansion. PCPC reported to NWDA that PDC would provide relocation services as it had in previous and current renewal projects.

NWDA wanted replacement housing to be located within the Northwest. Chairmen of NWDA sub-committees met with PDC. They discouraged new housing in the Good Samaritan urban renewal project. PDC was more optimistic, however, about a 10-block area with apartments. (NWDA Executive Board minutes, 12-1-70) 4-8-71.

2 Letter to Northwest Coordinating Group: from John Perry (PCPC),

3 Letter to Mayor Schrunk: from Good Samaritan Hospital, May, 1971.

4 NWDA minutes, 5-16-71.

5 Goals and Objectives for Planning Committee and Board; from Planning Staff, $12-2-71$.

6 NWDA work retreat, 11-20-71. 
CONCLUSION

This case study has identified and focused upon three potential sources of confusion regarding perceptions of the roles and role expectations of PCPC Staff and NWDA in working together to develop a Comprehensive District Plan. These three sources of confusion involved the issues of: (1) definition of citizen input and participation, (2) Staff accountability and (3) initiative and responsibility for tasks. The extent to which these sources of confusion effected joint Staff-NWDA planning depended upon the degree to which Staff and NWDA clarified their intentions in joint planning and were specific in communicating their goals, expectations and Iimitations in developing the District Plan.

Citizen Participation or Citizen Input

In general both Staff and NWDA agreed that their relationship should be a co-partnership, with Staff assuming the initiative in issues involving technical Input in plan development, and NWDA assuming the initiative in organizing and coordinating citizen input and backing for the plan. This was essentially the traditional non-political, technical planner role for Staff. The assumption was that NWDA possessed the same expertise in organizing citizen input and backing as Staff possessed expertise in compiling citizen input and developing a final plan report: together they could utilize their respective areas of expertise to produce a district plan.

In analyzing the citizen input which was broadly defined in the sequence of tasks to be performed by NWDA and Staff, essentially two levels of citizen Involvement were described. One level consisted of direct citizen involvement by the NWDA Board and Planning Committee. This board and planning committee was essentially an elite group consisting primarily of professionals. They 
tended to be more task than process oriented and saw their involvement in the plan as citizen input. They concentrated more on the plan itself rather than on involving and organizing area residents. Both Staff and NWDA saw the utility in working with a small group of individuals who could be reached on short notice and who could make decisions for the association and, therefore, the neighborhood.

However, to insure a second level of citizen participation, that is, broad neighborhood involvement in planning, Staff and NWDA agreed to use subcommittees and neighborhood review meetings. Since NWDA was to be the political arm in the plan development and, thus, be responsible for citizen input and backing for the plan, they assumed responsibility for involving citizens in the sub-committees and organizing the neighborhood review meetings. With respect to the sub-committees, both NWDA and Staff felt the sub-committees failed to involve citizens and to study the issues for which they were responsible. In analyzing the work accomplished by the Social Services sub-committee and the Business sub-committee, this fallure can be attributed to several factors. First, although Staff initially posed several questions to which the sub-committees should address themselves in developing neighborhood goals and objectives, the actual organization of the sub-committees and detailed work plans for each committee were left to the chairmen. The chairmen, all of them volunteers, had a Iimited amount of time to dedicate to NWDA. Hence, they often found it easier to formulate planning recommendations themselves or with one or two individuals, instead of planning meetings and involving more area residents. In addition, in the case of the Social Services sub-committee, neither NWDA nor PCPC Staff possessed expertise in soctal planning. Although they both stressed the need for a social service report for the plan, NWDA, upon whom the responsibility rested, did not appoint a new Social Services chairman when the original 
chairman left the district. NWDA showed more interest in the tangible aspects of the plan, such as zoning, land use, traffic and the freeway. In these cases not only was NWDA dealing with more concrete issues than "quality of life," but they also had the technical backing of the city planners. Thirdly, In the case of the Business sub-committee, NWDA did not have the perceived authority to involve large businesses in the area in planning. In general, business believed that NWDA was a residents' organization and not responsive to the needs of area business. Business preferred to use their established means of direct communication with City Hall and the Planning Commission. In sum, although NWDA accepted the responsibility of utilizing sub-committees to involve citizens in developing planning recommendations for the district, fallure by both NWDA and Staff to adequately assess the limitations of NWDA in meeting this responsibility contributed to the deficient utilization of these sub-committees. Staff assumed responsibility for the Business and Social Services sub-committees toward the end of the planning sequence.

In contrast to the sub-committees, both Staff and NWDA considered the neighborhood review meetings, especially those held during the summer, to be successful in involving the residents in the planning process. NWDA assumed their responsibility to plan for these meetings and located funds to hire a. community organizer for the summer. This organizer partialized the work to be done in preparing for and conducting the summer meetings. ffe assigned specific tasks to NWDA members, as well as scheduling meetings and notifying area residents. In summary, NWDA was able to fulfill its responsibility to provide citizen Involvement in the plan when this involvement was defined in specific tasks which were to be completed; when NWDA had the resources in terms of expertise, time and authority; and when Staff and NWDA were clear in their mutual 
expectations and limitations. If PCPC Staff are to plan with neighborhoods on a co-partnership basis, the NWDA experience suggests that the following issues involving the concept of citizen input should be resolved:

(1) For whom do district association members speak - for themselves or a specific constituency?

(2) If for a constituency, who? How much participation is necessary to insure that this constituency is represented?

(3) If obtaining broad citizen input is to be one of the responsibilities of a district association, is a volunteer association capable of assuming this task?

\section{Staff Accountability}

The confusion involving the role of Staff, in the joint Staff-NWDA relationship, was not so much the kind of technical assistance Staff was to provide but a question of their accountability and their constituency. Staff considered their role to be essentially planners for the Northwest Portland district, which was to be represented by NWDA. They saw their responsibility as utilizing input for the plan from all interests in the area. However, due to the fact that NWDA was basically a residents' association devoted to planning for livability, Staff was at times faced with the problem of planning with NWDA, yet having to consider the positions of other interests in the neighborhood, such as business, industry and Good Samaritan Hospital. Although Staff was working for the NWDA they were charged with developing a comprehensive plan for all of Northwest Portland.

NWDA members were concerned in two ways about the issue of Staff accountab1lity. Some felt that because Staff was paid by PCPC they could not be trusted completely. Others felt, and this became more pronounced as Staff gained greater acceptance in the NWDA, that the Staff, because of their close working relationship with NWDA, would be considered by PCPC as stding with the NWDA and thus weaken Staffs' recommendations to $\mathrm{PCPC}$. 
An issue of Staff accountability was raised when Staff was accused by Good Samaritan Hospital of aligning itself with NWDA against the hospital. Was Staff representing Northwest Portland of which Good Samaritan Hospital was - part, or was it only representing the NWDA?

When NWDA did not involve business in the planning, Staff conducted a survey of businesses in the area to gain their reaction to the plan. However, after the planning was completed and the final plan was being prepared by Staff, businesses in the Northwest did not see the plan as representative of their interests. Therefore, they hired their own planner to develop an alternate plan to represent their interests in the neighborhood. The question then seems to be, is the NWDA plan in fact a comprehensive plan for the entire district or is it only for the district residents?

Another issue which could have challenged Staff accountability was the development of a rival neighborhood association called Citizens for Northwest Survival. This group felt that NWDA was not accomplishing what it said it would and they proposed more activist tactics such as demonstrations opposing Good Samaritan Hospital expansion and the I-505 Freeway. Several hundred people turned out for one of these demonstrations. The organization disbanned when one member absconded with their funds; however, it did raise the issue of what PCPC Staff was to do in the case of rival neighborhood associations, when they too claim neighborhood backing. Fortunately, NWDA and Staff did not have to deal with this issue.

The Survival group and their fight against Good Samaritan Hospital raised another issue of Staff accountability. Good Samaritan Hospital is an important metropolitan hospital. Since Staff is employed by the City Planning Commission, they have a basic responsibility for the metropolitan area as a whole. What happens when a neighborhood association feels the good of the entire city is not 
in the best interest of their area, as in the hospital situation?

In general then, failure to clearly define Staff's constituency and clarify their accountability resulted in misunderstandings between Staff, NWDA and other district interests such as Good Samaritan Hospital and business. Staff and NWDA appeared to resolve the confusion with Good Samaritan Hospital; however, businesses in the area did not seem to be adequately planned for. If PCPC Staff is to work with future neighborhoods in developing a comprehensive plan for a district, the following issues involving staff accountability should be resolved:

(1) Is Staff to represent interests other than those of area residents? If so, which ones?

(2) How are these interests to be planned for?

(3) How is Staff to deal with its primary responsibility to the metropolitan area as a whole when it interferes with the interests of the neighborhood?

\section{Initiation and Responsibility for Planning Tasks}

A third source of confusion in the relationship between Staff and NWDA was the issue of responsibility for initiation and completion of various tasks. This issue was closely related to the issues involved in citizen participation. For example, Staff had to remind NWDA to organize the neighborhood meetings even though this was listed as one of NWDA's predetermined tasks. Also, Staff felt that NWDA had fallen down in the area of citizen involvement; however, they did not feel that it was their responsibility to do the organizing. In the case of the Social Services sub-committee, once the chairman had moved, it was the responsibility of the Planning Committee to replace this chairman. This was not done until three months before the plan was to be completed and then it was accomplished at Staffs' request. PCPC also hired a social planner at this 
time to assist in the formulation of a set of goals and objectives regarding social services for the district. The plan that was developed from general goals and objectives of NWDA Social Services sub-committee by the social planner and revised by NWDA resulted in an essentially hurried attempt at a skeletal outline for goals and objectives in the area of social planning for Northwest Portland.

Responsibility for certain tasks in the planning was never clearly defined. Planning Staff attempted to assume the responsibility of notifying NWDA of political decision-making effecting their area. (e.g., freeway hearings and zoning changes). This task had not been assigned to them, nor was it consistent with their technical non-political role. Staff did not feel that they had the time for complete responsibility and often they heard of important hearings too late for NWDA to develop a well thought out plan for protest.

This also raises the point of taking initiative for politically backing proposals. When NWDA developed their four additional points for the I-505 freeway study done by PCPC, they saw City Council as taking the initiative in backing their proposal. Yet at the hearing NWDA.did not present their four points in a way which communicated their demand for support. As a result they were dissatisfied with how their four points were presented to the Highway Commission.

In presenting the Comprehensive Plan to PCPC, the question of who takes the initiative for political backing again arose. This time Staff was concerned with NWDA's lack of involvement and forcefulness at the hearing but Staff's position did not permit them to advocate.

In summary, the confusion over the definition of citizen input in planning and confusion over Staff's constituency, produced a third source of confusionresponsibility for initiation and completion of tasks. 
Besides clarifying the issues of citizen input and Staff accountability the following issues involving responsibility and initiative for tasks should be resolved for future $\mathrm{PCPC}-$ neighborhood planning:

(1) How can goals in planning be defined more clearly so that specific tasks involved can be assigned?

(2) What is necessary to insure completion of agreed upon tasks?

\section{Summary}

In summary, PCPC Staff-NWDA planning was a pioneer project. Both Staff and NWDA had to define and redefine their roles and responsibilities throughout the planning process in order to develop some guidelines for their joint planning. Often, due to this lack of basic guidelines and misunderstandings regarding planning responsibility, planning was not carried out as effectively as it could have been. In spite of confusion and lack of clear-cut guidelines for planning, NWDA and Staff were able to develop a plan which reflected many of the district needs. In an attempt to identify some of the problems involved in planning, this paper has focused upon those issues around which Staff and NWDA expressed confusion as to their respective roles in joint planning. Realizing that no policy statement on neighborhood planning can cover all the problems which might be encountered but seeing the need for some basic policy for neighborhood planning, the following policy is offered, based on results of this study. 
To assure clarification of District Association and Staff roles and responsibilities, it is proposed that the city adopt a policy whereby a District Association (DA) contracts with the PCPC to provide broad citizen and neighborhood interest representation, as well as specific services in developing a district plan. To provide for broad citizen and neighborhood interest representation, the DA would specify the number of persons to serve on its board and the constituency to be represented by these board members. Seats on the board would be reserved for neighborhood committee chairmen, civic associations, community service associations, business and professional groups, churches, fraternal organizations, resource people, labor, special interest organizations (e.g., youth or elderly), and unafiliated organizations. During the pre-planning phase, the DA would negotiate with district interest groups to determine who would be represented and the degree of representation on the board. The DA would then negotiate with the PCPC over the representativeness of the proposed DA board. Once the contract with the DA was signed, the DA board would become the legal spokesman for district interests in the plan.

Since successful district planning requires broad citizen participation to assure acceptance and backing of a plan, the DA would also be contracting to provide a specified number of block meetings for a specified number of block groups throughout the planning period. Chairmen from these block groups would be voting members on the Board to assure citizen representation.

Besides specifying and contracting for neighborhood representation in the plan, the DA would also specify and contract for tasks to be completed in developing the district plan. Therefore, if a survey was to be used the DA would specify what it would provide in terms of volunteers and hours of service. If social planning was to be included the DA and the PCPC would specify what 
resources would be needed to accomplish this task. The DA would then have to negotiate with PCPC for professional resources to realize the task or locate private funds and sub-contract for the needed services. These provisions would be made before signing the contract with PCPC. By defining the tasks to be completed and identifying resources needed to accomplish these tasks, the DA is in a position to negotiate with the PCPC and arrive at a feasible plan for providing citizen input.

In order to provide the DA with staff to assist in developing a planning proposal and to assure maximum neighborhood involvement and utilization of neighborhood volunteers, the DA should have one full time community organizer to work with them. This community organizer is necessary to provide the DA with expertise in organizing the area residents and to partialize the planning tasks Into manageable segments which can then be undertaken by volunteer area residents. As such, he would provide for the maximum utilization of the DA's main resource-citizens. Since the role of the DA is essentially political, the community organizer would assist the DA in planning neighborhood meetings to facilitate citizen input and backing for the plan. He would be an advocate for the $D A$ and also facilitate their utilization of community resources. Funds for this organizer would be either alloted for by the city planning grant or from private sources. However, the organizer would be hired by and be responsible to the DA Board.

With the $D A$ and its organizer assuming a political role in the plan development, the PCPC Staff could assume a technical role. They would provide data, conduct studies, propose alternatives and draft the plan and plan documents. In suggesting alternatives, Staff would have to relate the proposed district plan to broader city-wide planning. 
Since the tasks of both DA and Staff would be specifically defined and contracted for, periodic evaluation would be requested. Therefore, when the Staff prepared an interim report on the plan, the DA would also prepare a report on neighborhood meetings, board activities, etc. This would enable periodic reevaluation of DA and Staff efforts in planning.

The process for a DA contracting with the PCPC would be along these general lines. First, the DA would apply for a planning grant. The DA would have letters of support from groups and organizations in the district. If the PCPC felt that the DA was representative of the neighborhood, the DA would be awarded a three month preplanning grant. During this time the DA would hire a community organizer, publicize its intentions for representation on the Board, establish its Board and, organize and develop a tentative proposal for joint DA-PCPC planning. This proposal should define tasks to be performed by the DA and resources needed. The DA would then negotiate with PCPC over Board representativeness and the planning proposal. The contract between DA and PCPC would then be signed.

During the planning phase Staff and DA would carry out their agreed tasks. There would be periodic evaluation of DA and Staff work to permit renegotiation of tasks if necessary.

Staff would then draw up the final neighborhood plan using the DA recommendations. The DA would approve this plan and a public hearing would be held before the City Council, at which time the City Council would accept, reject or amend the plan. If the plan is accepted, or accepted with amendments which are approved by the DA, it becomes the Comprehensive Plan for the neighborhood and no plans contrary to it may be taken, unless it is amended at a public hearing . 
The assumption of this study has been that in order to maintain democracy throughout government it is necessary that citizens participate in decision making which effects their lives. This suggests that in city planning there must also be citizen involvement. However, in this study it was shown that when citizens do participate in planning, confusion becomes focused upon the very issue of creating greater citizen involvement and participation.

To insure that this confusion is minimized, it is necessary to clearly define roles and role expectations. The establishment of a city policy-defining staff and citizen roles in joint planning is fundamental in minimizing this confusion. Allowing a DA to contract with PCPC enables clearer definitions of who is to take initiative and responsibility for tasks, for whom staff is accountable, and allows for a more adequate definition of citizen participation. This study has attempted to point out conflicting areas that develop when planners attempt to work with citizens. The guidelines which have been recommended seek to maximize both PCPC and neighborhood resources, human as well as technical, in planning together for a neighborhood. 


\section{BIBLIOGRAPHY}

Altshuler, Alan, "Decision-Making and the Trend Toward Pluralistic Planning", Urban Planning in Transition, New York, Grossman Publishers, Ernest Erber, ed., p. 183, 1970.

Arnstein, Sherry R., "A Ladder of Citizen Participation", Journal of the American Institute of Planners, PP. 216-224., July 1969.

Austin, David M., "Influence of Coumunity Setting on Neighborhood Action", Neighborhood Organization of Community Action, John B. Turner, ed., pp. 76-93, 1967 .

Cohen, Henry, "The Changing Role of the Planner in the Decision-Making Process", Urban Planning in Transition, Ernest Erber, ed., New York, Grossman Pub1ishers, p. 174, 1970 .

Reyes, Langeley, C., The Rehabilitation Planning Game; A Study in the Diversity of Neighborhood, Cambridge, Massachusetts, the MIT Press, 1969.

Mogulof, Melvin, "Coalition to Adversary: Citizen Participation in Three Federal Programs", Journal of the American Institute of Planners, pp. 225-232, Ju1y, 1969 .

Morris, Robert, and Martin Rein, "Emerging Patterns in Community Planning", Social Welfare Practice, New York, Columbia Inc. Press, p. 168.

Rabinovitz, Francine F., City Politics and Planning, New York, Atherton Press, 1969.

Warren, Ronald L., "Model Cities First Round: Politics, Planning and Participation", Journal of the American Institute of Planners, pp. 245-252.

Weissman; Harold H., Community Councils and Community Control: The Working of Democratic Mythology, University of Pittsburgh Press, 1970

Wilson, James Q., "Planning and Politics: Citizen Participation in Urban Renewal", Journal of the American Institute of Planners, p.247.

Making Democracy Work: A Study of Neighborhood Organization, New York, National Federation of Neighborhood Centers, 1966-1967.

Bartel, Frank, "Community Reaction May Snar1 Good Samaritan Hospital's Urban Renewal", The Oregonian, November 24, 1969.

Pintarich, Paul, "Youths Add Pep to NW Portland", The Oregonian, February 10, 1971.

Sanderson, William, "Northwest Portland Has Unique Opportunity to Plan", The Oregonian, March 14, 1969. 
Sanderson, William, "450 Hear Plans Revealed for NW Urban Renewal", The Oregonian, May 22, 1969.

The Oregonian, May 22, 1969.

The Oregonian, December 21, 1969. 